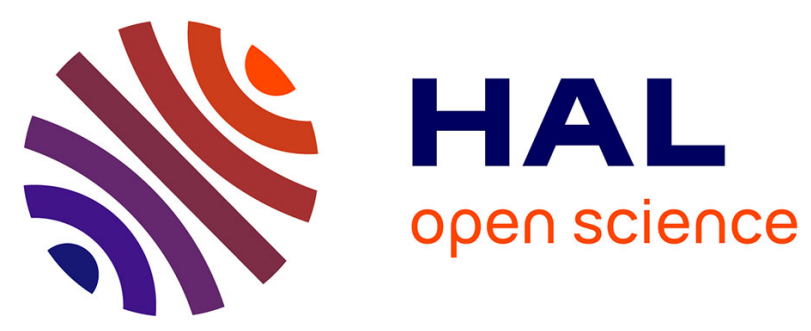

\title{
Effectiveness of a health promotion programme for long-term unemployed subjects with health problems: a randomized controlled trial
}

M Schuring, A Burdorf, a J Voorham, K Der Weduwe, J P Mackenbach

\section{- To cite this version:}

M Schuring, A Burdorf, a J Voorham, K Der Weduwe, J P Mackenbach. Effectiveness of a health promotion programme for long-term unemployed subjects with health problems: a randomized controlled trial. Journal of Epidemiology and Community Health, 2009, 63 (11), pp.893-n/a. 10.1136/jech.2008.080432 . hal-00477870

\section{HAL Id: hal-00477870 \\ https://hal.science/hal-00477870}

Submitted on 30 Apr 2010

HAL is a multi-disciplinary open access archive for the deposit and dissemination of scientific research documents, whether they are published or not. The documents may come from teaching and research institutions in France or abroad, or from public or private research centers.
L'archive ouverte pluridisciplinaire HAL, est destinée au dépôt et à la diffusion de documents scientifiques de niveau recherche, publiés ou non, émanant des établissements d'enseignement et de recherche français ou étrangers, des laboratoires publics ou privés. 
Effectiveness of a health promotion programme for long-term unemployed subjects with health problems: a randomized controlled trial

M. Schuring ${ }^{1}$, A. Burdorf ${ }^{1}$, A.J. Voorham ${ }^{2}$, K. der Weduwe $^{2}$, J.P. Mackenbach ${ }^{1}$

1 Department of Public Health, Erasmus MC, Rotterdam, The Netherlands

2 Municipal Health Service GGD Rotterdam, Rotterdam, The Netherlands

Correspondence address:

Alex Burdorf, $\mathrm{PhD}$

Department of Public Health

Erasmus MC

PO Box 2040

3000 CA Rotterdam

The Netherlands

Fax: +31-10-7038475

E-mail: a.burdorf@erasmusmc.nl

Word count: 4502 


\begin{abstract}
Background: Employment status is an important determinant of health inequalities. Among unemployed persons a poor health decreases the likelihood of re-employment. Methods: A randomized controlled trial with 6 months follow up. Unemployed persons with health complaints receiving social security benefits were randomized with 456 persons assigned to the usual care group and 465 persons assigned to the intervention group. The intervention consisted of three sessions of three hours each every week during a 12-week period. One session focused on education to enhance the ability to cope with (health) problems and two sessions constituted of physical activities to improve physical health. The primary outcome measures were perceived health, measured by the Short Form 36 Health Survey, and psychological measures mastery, self esteem, and painrelated fear of movement. Secondary outcome measures were work values, job search activities, and re-employment.

Results: Enrollment in the intervention programme was $65 \%$ and $72 \%$ completed the programme with over $70 \%$ of attendance to all sessions. The intervention had a good reach among subjects with lower education, but had no effect on mental and physical health, mastery, self esteem, and pain-related fear of movement. Participation in the programme had no influence on work values, job search activities, or re-employment. Conclusion: The intervention programme aimed at improvement of physical and mental health of unemployed people with health complaints did not show beneficial effects. The lack of integration into regular vocational rehabilitation activities may have interfered with these findings. It cannot be recommended to implement this particular health programme.
\end{abstract}




\section{Introduction}

The relationship between unemployment and poor health has been well established, as demonstrated by a higher prevalence of illness and disability [1,2] and a higher mortality among unemployed people.[3] The association between health and employment is bidirectional: unemployment may cause poor health (causation hypothesis), and poor health may increase the probability of unemployment (selection hypothesis).[4-6]

Work provides a variety of features, including the use of skills, interpersonal contact, and provision of economic resources, that are responsible for psychological wellbeing and are adversely influenced by job loss and unemployment.[7] Job loss may lead to impaired role and emotional functioning, poor health, and depression.[8] Self-esteem declines with job loss [9] and a low self-esteem is a determinant of self-reported poor health.[10] A poor psychological health will act as a barrier to return to paid employment through a decreased motivation, lowered expectations in finding employment, and ineffective job seeking.[8, 9, 11] Thus, unemployment may lead to a poorer health, which in turn will reduce the likelihood of re-employment.

In order to increase the possibilities for re-employment, improvement in health of unemployed persons may, therefore, be an important step. Unemployed persons with chronic health complaints, such as musculoskeletal disorders, may become progressively less healthy, since fear of pain and reinjury may lead to reduced activities [12], resulting in a passive life style with low levels of physical activity.[13, 14] Hence, exercises to improve physical activity may be beneficial, not only for those subjects with disorders of the locomotive system, but also for other chronic diseases as well, including heart and pulmonary diseases and depression.[15] Cognitive-behavioural therapy may be needed to target specific pain-related beliefs and coping strategies for modification.[16] Rose and Harris [17] have identified cognitive behavioural therapy as a promising intervention to improve the psychological health of persons who are unemployed. Recently, Watson and colleagues [18] have provided some indications that a combined physical exercise and cognitive behavioural programme improved physical fitness as well as increased employment rates among unemployed participants with health complaints. These results should be interpreted with caution, however, since the voluntary participation in the 
programme might have biased towards participants with a high motivation and a positive attitude towards (return to) work.

Hence, there is a need for randomized trials on multidisciplinary health intervention on unemployed persons. The aim of the current study ("Work on your health") was to evaluate the effectiveness of a health promotion programme, consisting of physical exercise and cognitive training, on physical and mental health of unemployed subjects with health complaints. 


\section{Methods}

\section{Design and study population}

The study was designed as a randomized controlled trial (RCT) and approved by the Medical Ethics Committee of the University Medical Center Rotterdam Erasmus MC. Persons on social security benefits who (partly ) attributed their inability to find a paid job to their chronic health problems, were referred by the Employment Centre of the City of Rotterdam, The Netherlands, for a fit-to-work test, conducted by a physician, psychologist, and an employment specialist. All participants with health problems and declared to be capable of full time employment were selected as target population for this study. For more than two third of the population (68\%) the presence of chronic pain was ascertained by a physician. In addition, subjects were required to understand and speak Dutch at basic level.

\section{$\underline{\text { Randomization }}$}

Randomization was performed by a researcher with a computer-generated list of random numbers (SAS Software, version 8.12, Cary, NC). At the company that performed the fitto-work tests, every week the researcher allocated all participants to the intervention group or the reference group. From December 2004 until December 2007, every participant who met the inclusion criteria was randomized. After randomization eligible participants were approached by the research team for participation in the study and asked to provide their written informed consent. This procedure of informed consent after randomization was necessary, since the City of Rotterdam required an immediate referral to an employment service for vocational rehabilitation without further administrative delay, and also required that willingness to participate in the study would not interfere with existing requirements for job search.

The allocation sequence was concealed until the participant had been assigned. The participants and the professionals providing the intervention could not be blinded. However, the persons who were involved in data collection and data entry were blinded, since data collection was conducted completely independent from the intervention and regular vocational rehabilitation. 
Figure 1 shows the diagram of the flow of participants through the phases of the trial. In total, 465 subjects were assigned to the intervention programme and 456 subjects to the usual care group.

\section{Intervention}

The intervention was aimed at changing the way unemployed persons perceive and cope with their health complaints. The rationale was based on the biopsychosocial model of chronic pain and subsequent interdisciplinary pain management approach. Patients with chronic pain are at increased risk for emotional disorders (such as anxiety, depressions, and anger), maladaptive cognitions (such as catastrophizing and poor coping skills), functional deficits and physical deconditioning (due to decreased physical activity and fear of injury). These effects are often interdependent, so that one cannot simply treat one to the exclusion of others. Interdisciplinary pain management embraces the fact that the comprehensive treatment of all these dimensions is needed in order to be effective.[19]

The intervention consisted of three sessions each week during a 12-week period. Every week one session of three hours was focused on behavioural education and two sessions were focused on physical activity. The behavioural educational component was designed to enhance a participant's insight in his/her health complaints, to increase positive coping with health problems by reducing fear and avoidance of movement, to enhance self-esteem and feelings of mastery, and to improve functioning by learning to think positively and enhance social skills. This part was conducted by two prevention workers.

The physical activity component consisted of two sessions of three hours. The first session comprised of 1.5 hours fitness training (cardio and weight training) and 1.5 hours of indoor sports (e.g. basketball, swimming). The second session comprised of 1.5 hours fitness training and 1.5 hours of outdoor activities. The intervention was designed to make the participants aware that it was safe to move and healthy to be physically active, to extend the social network, to improve daily structure, and to improve general wellbeing. The exercise programme was developed according to the graded-activity principle.[20-22] The exercises started below the average functional capacity assessed 
during the first session and were increased gradually during the course of the intervention, according to the time-contingency principle. These sessions were conducted by physical education teachers.

\section{$\underline{\text { Usual care }}$}

Subjects in the reference group were referred to one of the three vocational rehabilitation services in the area. They provided a standardized approach of vocational rehabilitation, characterized by a broad re-orientation on employment and employability, enhancement of job search skills, and intensification of job search efforts. The usual care approach did not include any activity related to health, such as health promotion to increase physical activity in leisure time.

\section{$\underline{\text { Data collection }}$}

A questionnaire and an informed consent was send to the home address of the participants, followed by two reminders two respectively four weeks later. Additional actions were undertaken to include more subjects. The questionnaire and covering letter were translated in Turkish and send in addition to the Dutch questionnaire to subjects with a Turkish surname. If subjects of the study population needed help with filling in the questionnaire, they could get in touch with an interviewer. Subjects who did not reply to the postal questionnaire were visited by an interviewer at their home address with four attempts at different day times during a two week period. The interviewers were matched with subjects, based on ethnicity, age, and gender, and could offer an interview in the mother tongue (Dutch, Arabic, or Turkish).

\section{$\underline{\text { Socio-demographic variables }}$}

Socio-demographic variables, such as ethnic background, education, age, sex, and marital status were included in the study. Ethnic background of the respondent was based on the country of birth of the mother. In case the mother was born in The Netherlands, the country of birth of the father was leading.[23] Different ethnic groups were defined, based on differences in experiences of migration (refugees or labour migrants) and differences in geographical and cultural distance from the Netherlands. Three ethnic 
minority groups were defined: 1) Turks and Moroccans, 2) Antilleans and Surinamese, and 3) a miscellaneous group with all other countries of origin. Subjects were divided into three groups according to the highest level of educational attainment. A high educational level was defined as higher vocational training or university, intermediate educational level was defined as higher secondary schooling or intermediate vocational training, and low educational level was defined as no education, primary school, lower and intermediate secondary schooling or lower vocational training. Marital status was used to distinguish those subjects married or living together from others.

\section{Primary outcome measures}

Health measures

Health related quality of life was measured with the Dutch version of the Short Form 36 Health Survey (SF-36).[24, 25]. Self-reported health (SRH) was measured with the first item of the SF-36 by asking subjects to rate their overall health on a five-point scale, ranging from 'excellent', very good', 'good' and 'fair' to 'poor'. Those reporting less than 'good health' were defined as having a poor health.[26]

The other 35 items of the SF-36 were used to calculate scores on eight dimensions: physical functioning, general health, mental health, bodily pain, social functioning, vitality, role limitation due to emotional health problems, and role limitation due to physical health problems. Scores could range from 0 to 100, with a higher score indicating a better health related quality of life.

\section{Psychological measures}

Mastery was measured by the Personal Mastery Scale [27], which consists of seven items (eg "I have little control over the things that happen to me", "There is little I can do to change many of the important things in my life"), answered on a four point Likert scale (strongly agree to strongly disagree). Average scores across items were calculated, ranging from 1 to 4 , with a higher score indicating a higher level of mastery. In case three or more items were unanswered, no score was computed (Cronbach's alpha=0.69). 
Self-esteem was measured with the Rosenberg Self-Esteem Scale [28], with 10 items (e.g., "On the whole, I am satisfied with myself", "All in all, I am inclined to feel that I am a failure"), answered on a four point Likert scale (strongly agree to strongly disagree). Average scores across items were calculated again, ranging from 1 to 4; a higher score indicated a higher level of self-esteem. In case three or more items were unanswered, no score was computed (Cronbach's alpha=0.84).

Kinesiophobia was measured with the Tampa Scale of Kinesiophobia [29], which consists of 17 items on fear of movement and injury (eg, "It's really not safe for a person with a condition like mine to be physically active", "Pain always means I have injured my body") on a four point Likert scale (strongly agree to strongly disagree). Average scores across items were again calculated, ranging from 1 to 4 , with a higher score indicating a higher level of kinesiophobia. In case five or more items were unanswered, no score was computed (Cronbach's alpha=0.80).

\section{Secondary outcome measures}

Attitudes and values towards paid employment were measured with five questions (e.g., "I would do anything to get a job", "If you don't want to work, you take advantage of others") on a five point scale (strongly agree to strongly disagree). A sum score was also calculated (Cronbach's alpha=0.30). Job search activities were measured with five questions concerning different types of job search activities (e.g., "writing an application letter", "searching for vacancies in the newspaper or on the internet"). A sum score was calculated, ranging from 0 (no job search activities) to 5 (many job search activities) (Cronbach's alpha=0.68). Finally, re-employment was measured with one question ("Do you currently have a paid job?") on a dichotomous scale (yes/no).

\section{$\underline{\text { Process evaluation }}$}

At the end of the intervention programme semi-structured interviews were undertaken with ten participants and ten trainers to obtain more qualitative insight into different aspects of the intervention that could be improved in the future. 


\section{$\underline{\text { Statistical analysis }}$}

Based on the sample size calculation with an initial participation of $70 \%$ and a loss-tofollow-up of $30 \%$ (power of $80 \%$, one-sided significance level 0.05 ), a difference of 5.0 points $(10 \%)$ in the scores on health measures between the intervention group and reference group could be detected with 400 persons assigned to both trial arms and 196 persons with complete data collection in each group. With these assumptions a difference of $10 \%$ in proportion of entering paid employment between the intervention (15\%) and control group (5\%) could be detected.

The effects of individual characteristics and physical and mental health on participation in the intervention were investigated by logistic regression analysis. The dependent variables were failure to start with the programme (yes/no) and dropping out of the programme (yes/no). Independent variables with a p-value of 0.10 or less were retained in the multivariate models as well as age and gender by default. In order to compare both analyses, a variable retained in one multivariate model was also included in the other multivariate model.

The baseline characteristics of both groups were compared with the chi-square test for dichotomous data and the t-test for continuous data. The effects of the intervention on outcome measures at 6 months follow-up were analyzed according to the intention-to-treat principle, including all subjects regardless of whether or not they actually received the complete intervention. The analysis was conducted with all available respondents at the time of follow-up and a non-response analysis was conducted to evaluate whether drop-out during the follow-up period was associated with health status or intervention status. An imputation technique for missing responses on health outcomes during follow-up measurements was not used, since the choice for a particular imputation method may influence the estimation of the intervention effect.[30] The effects of the intervention on the continuous outcome measures were evaluated with a mixed effect model for repeated measurements, with the intervention as fixed effect and a compound symmetry covariance structure for the random variation between persons and across persons. This approach estimates the change in an outcome measure between baseline and follow-up, taking into account the baseline value of the outcome measure of 
interest and the potential confounders age, sex, ethnicity, education, and time on benefits (SAS version 8.12 - procedure Mixed).

The effects of the intervention on the dichotomous outcome measure reemployment was analyzed by a chi-square method (SAS version 8.12 - procedure Surveymeans), adjusted for sex and age. All analyses were carried out with the statistical package SAS version 8.12. 


\section{Results}

Figure 1 shows that at baseline 921 subjects were enrolled in the study. In the intervention group 343 (74\%) persons returned the first questionnaire, which was statistically significantly higher than the $310(68 \%)$ respondents in the reference group. Non-response was not influenced by age or sex.

The response at follow-up did not differ between the intervention group ( $n=176$; $51 \%)$ and reference group $(\mathrm{n}=150 ; 48 \%)$. Loss-to-follow up was statistically significantly higher among men, but not related to age, marital status, education, ethnic background, work experience, duration on benefit, or health at baseline. Within the intervention group, participation in the intervention was not associated with response on the follow-up questionnaire.

Table 1 shows that the randomization was successful in creating study groups with similar demographic characteristics and physical and psychological health at baseline.

Among the 465 subjects who were allocated to the intervention group, 300 subjects $(65 \%)$ initially started with the health programme. During the health programme 85 subjects (28\%) dropped out of the intervention due to an attendance level below $70 \%$ of all session offered (table 2). Initial participation was not influenced by age, ethnic background, educational level, marital status, employment history, or perceived health. Men were more likely to not enter the intervention programme $(\mathrm{OR}=1.5)$. Subjects dropping out of the programme reported poorer physical and mental health at baseline (table 3). High fear of movement at baseline did have a significant effect on dropping out of the programme in the univariate model $(\mathrm{OR}=2.095 \% \mathrm{CI} 1.0-3.9)$. However, due to the associations of fear of movement with mental health $(\mathrm{r}=0.3)$ and physical functioning $(\mathrm{r}=0.4)$, the effect of fear of movement on dropping out of the programme was not significant in the multivariate model.

\section{Effects of the intervention}

Table 4 shows that the intention-to-treat analysis demonstrated no beneficial effects of the intervention on health and psychological outcome measures. There was no effect on employment status at 6 months follow up (re-employment: $2.0 \%$ in refrence group versus 
$2.2 \%$ in intervention group, estimated difference $0.3 \%(-1.9 \%-2.3 \%))$. In addition, attitudes and values towards paid employment, and job search activities were not altered by the intervention. The effect sizes of the individual parameters as well as the sum scores across scales were all close to unity (data not shown)

\section{$\underline{\text { Subgroup analyses }}$}

A per protocol analysis of subjects who initially participated in the intervention and a subgroup analysis of subjects who participated at least $70 \%$ of the intervention did not show positive effects of the intervention. (data not shown)

Subgroup analyses based on subjects with musculoskeletal complaints or subjects with psychological complaints showed that the intervention was not effective in either subgroup. The effect sizes were all close to unity and did not differ from the overall effect size (data not shown)

\section{Effect of a co-intervention}

During the follow-up of 6 months, 80 subjects in the intervention group (23\%) and 56 subjects in the reference group (19\%) started with a job search training. This cointervention did not influence the observed lack of any effect of the intervention. 


\section{Discussion}

The health promotion programme did not show positive effects on perceived mental and physical health, self esteem, mastery, and fear of movement. In addition, values and attitudes towards paid employment, job search activities, and employment status at six months follow up were not affected by the health programme either.

There are three possible reasons why the intervention was not effective: 1) the study could not demonstrate an effect due to methodological limitations; 2) the intervention was not successfully implemented; or 3) the intervention was indeed not effective in this form.

\section{Methodological limitations}

Eligible participants were randomized before they were approached by the research team for participation in the study. This procedure was necessary since the City of Rotterdam required an immediate referral to an employment service without further administrative delay. As a consequence of this procedure, the non response on the first questionnaire after randomization was relatively high. The response to the first questionnaire was slightly higher in the intervention group (74\%) compared with the reference group (68\%). Receiving an invitation to participate in a health programme may have influenced the decision to fill out the questionnaire, but this had little influence on the comparability of intervention and reference group.

Data collection was conducted completely independent from the intervention programme and regular vocational rehabilitation, since participation in these activities was partly mandatory, whereas participation in this study was completely voluntary. As a consequence, some subjects who filled out the questionnaire did not take part in the intervention, whereas other subjects took part in the intervention but did not respond on the questionnaire. For most subjects the reason for not taking part in the intervention or the vocational rehabilitation was unknown, although a small proportion was due to termination of the benefits for different reasons (moving in with a partner or moving out of the city of Rotterdam). However, participation in the intervention was not influenced 
by personal characteristics, employment history, or perceived health. Therefore, it is assumed that there was no selection bias in initial participation in the programme.

The power calculation was based on 196 subjects per group with complete data collection. In fact, the achieved sample was considerably less. Since the estimated effects of the intervention were close to unity for all parameters, a larger study population would not have resulted in statistically significant effects of the intervention. Therefore, it is assumed that the failure to detect between-group differences is not due to a lack of power of the study.

In this study perceived health was an important outcome measure, whereas the focus of the intervention programme was also on improving objective physical health. In the intervention group it was shown that a better cardiorespiratory fitness did not result in a better perceived health.[31]

Another methodological reason for not finding any effect of the health programme may have been the absence of an assessment of change immediately after the end of the intervention. Theoretically, there could have been a positive effect on health directly after the programme was finished, which had already faded away at the time of follow up, on average about three months after the programme termination. However, this would imply a lack of sustainability of the intervention. In the design of the study a vocational training directly after the end of the health program was thought to be able to sustain possitive effects of the intervention. However, in practice the vocational training was often delayed or did not start at all. Due to organisational problems of the social security service and vocational rehabilitation centres only $23 \%$ of the intervention group and $19 \%$ of the control group started with a vocational training within the follow up period of six months. This lack of follow-up activities concerning vocational rehabilitation can be considered as an implementation failure and may have interfered with our results.

\section{The intervention was not successfully implemented}

The intervention was offered during two years in eight periods with three groups per period. In total, 22 groups started with the programme with 11 to 22 participants per group. Theoretically, each programme consisted of 12 weeks of multidisciplinary 
rehabilitation. In practice, however, participants received only nine weeks of effective training, since three weeks were lost due to the time it took for the introduction and intake and outtake activities.

Participation in the health programme was mandatory, but the social security service of the city of Rotterdam did not strictly enforce actual participation. The mandatory nature has undoubtedly resulted in an increased participation. Participants who fell obliged to join, may not have experienced a need to improve their health. Feedback provided by the physical education teachers indicated that getting participants involved was a major challenge in itself and that an increase in training effort in a timecontingent manner will certainly not have been achieved by all participants. Hence, the graded activity principle was not adhered to for all participants.

Interviews with ten participants and the trainers revealed that the cognitive training was not well adapted to this study population of persons with low education and low socio-economic status. Both trainers and participants acknowledged that the cognitive training should be improved with less focus on theory and being more adapted to experiences in daily life of the participants.

Among the persons who initially started with the intervention, $72 \%$ completed the programme with more than $70 \%$ attendance to all sessions offered. Hence, the intervention had a good reach among subjects who are usually difficult to engage in health promotion activities. Only $28 \%$ did not succeed to participate in at least $70 \%$ of the programme activities. Participants with a poor physical and mental health and high fear of movement at baseline had a higher chance of dropping out during the programme compared to persons with a good health and no fear of movement. This may have affected the effectiveness of the health programme, because those persons who could potentially benefit the most dropped out of the programme. However, a subgroup analysis of the subjects who participated in at least $70 \%$ of all sessions in the programme versus the reference group, did not show any positive effects of the intervention.

\section{The intervention was indeed not effective in this form.}

A systematic review concluded that only intensive (>100 hours) multidisciplinary rehabilitation will reduce pain and improve function in patients with chronic low back 
pain.[32] Based on this criterion, it is assumed that the intensity of our programme was high enough (around 108 hours), but the subgroup analysis showed that participants with low back pain did not improve in their pain, physical function, or any of the other outcome measures in the current study. Bendix et al.[12] showed that a multidisciplinary intensive programme that ran for 3 successive weeks of 39 hours per week was effective, whereas the health programme under study ran for 12 successive weeks with 9-12 hours per week. A more intensive programme with a shorter duration may be more effective than a less intensive programme with a longer duration.

An anticipated result of the health programme was a higher re-employment in the intervention group. A multidisciplinary rehabilitation programme, described by Watson et al. [18], with a strong focus on improvement in the ability to work and on actual return to work, showed that at 6 months follow-up 38\% of subjects were employed and another $23 \%$ were in voluntary work of education/training. In contrast, in the health programme offered in Rotterdam return to work was not part of the individual goal setting. The lack of a strong integration of the health-oriented intervention into the regular vocational rehabilitation activities may have impeded beneficial effects. Patel et al. [33] has suggested that multidisciplinary approaches should not only be concerned with medical and psychological issues, but should also address the obstacles to return to work as seen by the patient.

The process evaluation showed that after the end of the programme, most people fell back into their old lifestyle with low levels of physical activity. In order to have sustainable effects of a health promotion programme, it is important that participants continue to be physically active. The absence of a sustained effort by health counsellors after termination of the intervention to encourage participants to stay physically active may have contributed to the fact that no health effects were found.

In conclusion, the intervention aimed at the promotion of physical and mental health of unemployed persons with health complaints did not show any beneficial effects. Thus, it cannot be recommended to implement this particular health promotion programme to counteract at individual level the negative effects of unemployment on health. Measures on societal level to reduce the negative effects of unemployment on 
population health are required [11]. In policies for health equity, it remains of paramount importance to develop measures to include people with a poor health in the labour market.

\section{Acknowledgements}

Funding for this study was provided by the Public Health Fund (Fonds OGZ) of the Netherlands (reg. nr. P161). We greatfully acknowledge the dedication of the professionals providing the health promotion programme (Ergocontrol) and their continuous support to this study. 


\section{What this paper adds}

What is already known on this subject?

- Unemployment may cause poor health, and poor health may increase the probability of unemployment.

- There are some indications that a combined physical exercise and cognitive behavioural programme may improve physical fitness as well as increase employment rates among unemployed persons with health complaints.

- There is a need for randomized trials on multidisplinary health interventions on unemployed persons with health complaints.

What does this study add?

- The health promotion intervention had a good reach among unemployed subjects with health complaints, who are usually difficult to engage in health promotion activities

- The intervention to enhance the ability to cope with health problems and to improve physical activities had no effect on mental and physical health nor any effect on work values, job search activities, or re-employment.

- The lack of integration into regular vocational rehabilitation activities may have negatively affected the results of the health programme among unemployed persons 
Figure $1 \quad$ Flow of participants through the phases of the trial. 
Table 1 Characteristics of the study population and baseline values of outcome measures

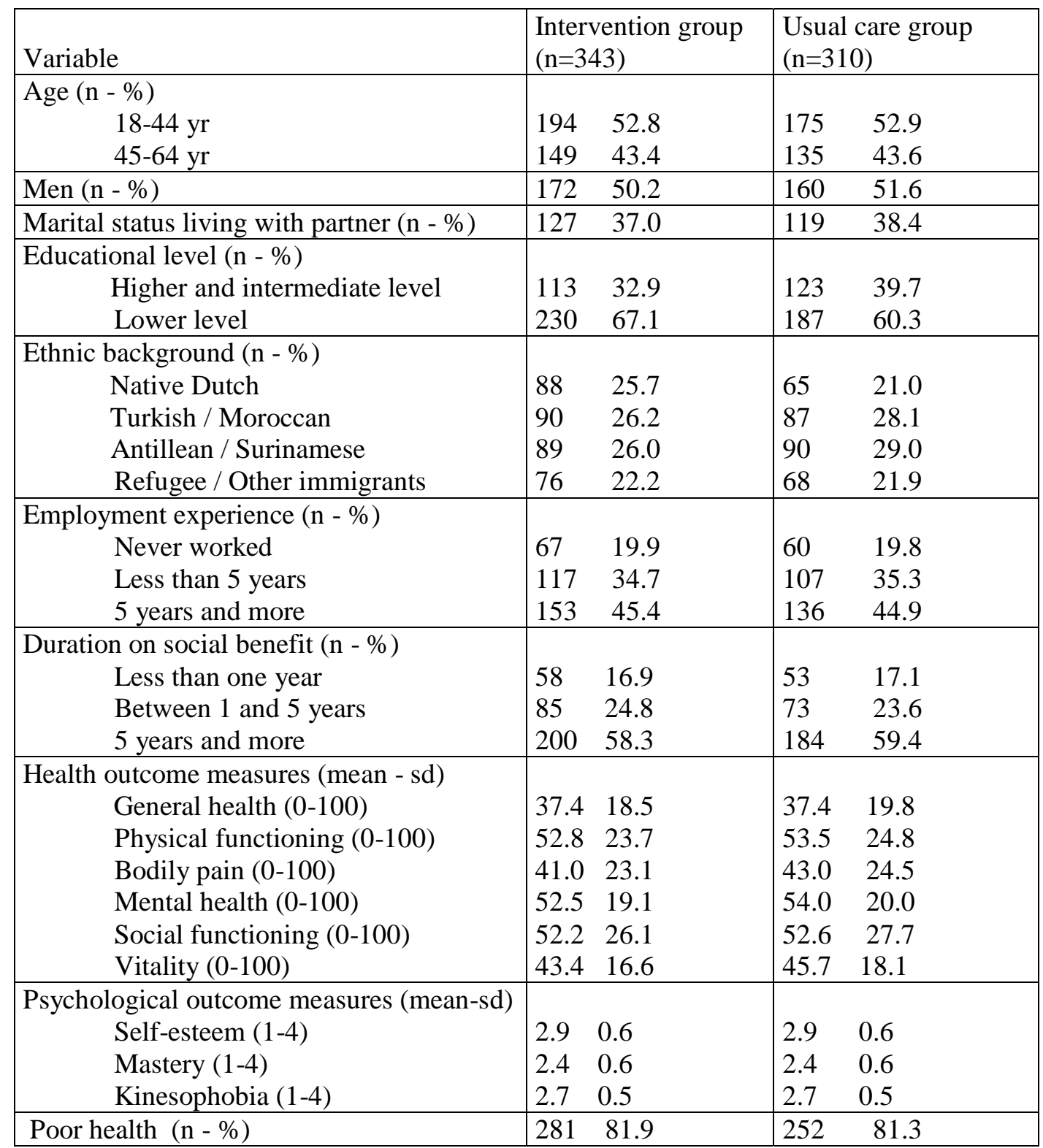


Table 2 Number of subjects who started with the health programme, who continued their participation throughout the programme, and subjects who dropped out during the programme.

\begin{tabular}{|l|l|l|}
\hline & $\begin{array}{l}\text { Number of subjects } \\
\mathrm{N}(\%)\end{array}$ & $\begin{array}{l}\text { Number of } \\
\text { respondents to the } \\
\text { first questionnaire } \\
\mathrm{N}\end{array}$ \\
\hline Allocated to intervention & 465 & 343 \\
\hline Initial participation & $300(65)$ & 239 \\
\hline $\begin{array}{l}\text { Continued participation } \\
\text { (> 70\% attendance to all sessions) }\end{array}$ & $215(72)$ & 172 \\
\hline $\begin{array}{l}\text { Drop out: } \\
\text { Between 50-70\% participation } \\
\text { Less than 50\% participation }\end{array}$ & $\begin{array}{l}41 \quad(14) \\
44(15)\end{array}$ & 30 \\
\hline
\end{tabular}


Table 3 Logistic regression analysis on the effects of individual characteristics and mental and physical health on failure to start with the programme or dropping out during the programme

\begin{tabular}{|c|l|l|}
\hline Variable & $\begin{array}{l}\text { Not starting with } \\
\text { programme } \\
(\mathrm{n}=104 / 343) \\
\text { OR }(95 \% \mathrm{CI})\end{array}$ & $\begin{array}{l}\text { Dropping out } \\
(\mathrm{n}=67 / 239)\end{array}$ \\
\hline Age & 1.0 & 1.0 \\
$18-44 \mathrm{yr}$ & $0.7(0.4-1.1)$ & $0.9(0.5-1.7)$ \\
$45-64 \mathrm{yr}$ & $1.5(0.9-2.5)^{*}$ & $0.9(0.5-1.7)$ \\
\hline $\begin{array}{l}\text { Men } \quad \begin{array}{l}\text { OR }) \\
(\text { standardised values }) \\
\text { Physical functioning } \\
\text { Mental health }\end{array} \\
1.0(0.8-1.3)\end{array}$ & $\begin{array}{l}0.8(0.5-1.1)^{*} \\
0.7(0.5-1.0)^{*}\end{array}$ \\
\hline
\end{tabular}

$* 0.05<\mathrm{p}<0.10$

$\mathrm{OR}=$ odds ratio, $\mathrm{CI}=$ confidence interval 
Table 4 Outcome measures at follow up in the intervention and usual care group and the estimated effect of the intervention

\begin{tabular}{|c|c|c|c|c|}
\hline & $\begin{array}{l}\text { No. of } \\
\text { participants } \\
\text { intervention/usual } \\
\text { care }\end{array}$ & $\begin{array}{l}\text { Intervention } \\
\text { group } \\
\text { mean (sd) }\end{array}$ & $\begin{array}{l}\text { Usual care } \\
\text { group } \\
\text { mean (sd) }\end{array}$ & $\begin{array}{l}\text { Estimated effect } \\
\text { (difference) }\end{array}$ \\
\hline \multicolumn{5}{|l|}{ Health outcome measures } \\
\hline General health $(0-100)$ & $172 / 146$ & $40.7(18.6)$ & $36.9(22.3)$ & $1.1(-0.9-3.0)$ \\
\hline Physical functioning (0-100) & $174 / 147$ & $54.9(24.2)$ & $53.8(25.2)$ & $0.1(-2.2-2.5)$ \\
\hline Bodily pain (0-100) & $173 / 147$ & $45.6(24.5)$ & $44.5(23.9)$ & $0.7(-1.7-3.2)$ \\
\hline Mental health (0-100) & $173 / 148$ & $54.8(17.8)$ & $53.4(21.7)$ & $0.4(-1.5-2.3)$ \\
\hline Social functioning (0-100) & $173 / 149$ & $55.1(23.3)$ & $53.7(28.2)$ & $0.5(-2.3-3.3)$ \\
\hline Vitality $(0-100)$ & $173 / 148$ & $45.1(16.7)$ & $43.8(18.7)$ & $0.6(-1.2-2.4)$ \\
\hline \multicolumn{5}{|l|}{ Psychological outcome measures } \\
\hline Self-esteem (1-4) & $172 / 146$ & $2.8(0.6)$ & $2.9(0.6)$ & $-0.06(-0.1-0.0)$ \\
\hline Mastery (1-4) & $161 / 135$ & $2.5(0.6)$ & $2.5(0.7)$ & $-0.05(-0.1-0.0)$ \\
\hline Kinesophobia (1-4) & $172 / 146$ & $2.6(0.5)$ & $2.7(0.5)$ & $-0.01(-0.1-0.1)$ \\
\hline
\end{tabular}

Difference was adjusted for age, gender, ethnic background, education, duration on benefit and also for baseline values of health and psychological measures. 


\section{References}

[1] Claussen B. Health and re-employment in a five-year follow-up of long-term unemployed. Scand J Public Health 1999;27:94-100.

[2] Janlert U. Unemployment as a disease and diseases of the unemployed. Scand J Work Environ Health 1997;23 Suppl 3:79-83.

[3] Morris JK, Cook DG, Shaper AG. Loss of employment and mortality. BMJ 1994;308:1135-9.

[4] Bartley M, Sacker A, Clarke P. Employment status, employment conditions, and limiting illness: prospective evidence from the British household panel survey 1991-2001. J Epidemiol Community Health 2004;58:501-6.

[5] Schuring M, Burdorf A, Kunst AE, Mackenbach JP. The effect of ill health on entering and maintaining paid employment: evidence in European countries. J Epidemiol Community Health 2007;61:597-604.

[6] Thomas C, Benzeval M, Stansfeld SA. Employment transitions and mental health: an analysis from the British household panel survey. J Epidemiol Community Health 2005;59:243-9.

[7] Warr P, Jackson P. Adapting to the unemployed role: a longitudinal investigation. Soc Sci Med 1987;25:1219-24.

[8] Price RH, Choi JN, Vinokur AD. Links in the chain of adversity following job loss: how financial strain and loss of personal control lead to depression, impaired functioning, and poor health. J Occup Health Psychol 2002;7:302-12.

[9] Eden D, Aviram A. Self-efficacy training to speed reemployment: Helping people to help themselves. Journal of Applied Psychology 1993;78:352-60.

[10] Cott CA, Gignac MA, Badley EM. Determinants of self rated health for Canadians with chronic disease and disability. J Epidemiol Community Health 1999;53:731-6.

[11] Creed PA. Improving the mental and physical health of unemployed people: why and how? Med J Aust 1998;168:177-8.

[12] Bendix AF, Bendix T, Ostenfeld S, Bush E, Andersen. Active treatment programs for patients with chronic low back pain: a prospective, randomized, observerblinded study. Eur Spine J 1995;4:148-52.

[13] Claussen B, Bjorndal A, Hjort PF. Health and re-employment in a two year follow up of long term unemployed. Journal of Epidemiology and Community Health 1993;47:14-8.

[14] Lakka TA, Kauhanen J, Salonen JT. Conditioning leisure time physical activity and cardiorespiratory fitness in sociodemographic groups of middle-ages men in eastern Finland. Int J Epidemiol 1996;25:86-93.

[15] Pedersen BK, Saltin B. Evidence for prescribing exercise as therapy in chronic disease. Scand J Med Sci Sports 2006;16 Suppl 1:3-63.

[16] Turner JA, Jensen MP, Romano JM. Do beliefs, coping, and catastrophizing independently predict functioning in patients with chronic pain? Pain 2000;85:115-25.

[17] Rose V, Harris E. From efficacy to effectiveness: case studies in unemployment research. J Public Health (Oxf) 2004;26:297-302. 
[18] Watson PJ, Booker CK, Moores L, Main CJ. Returning the chronically unemployed with low back pain to employment. Eur J Pain 2004;8:359-69.

[19] Gatchel RJ, Peng YB, Peters ML, Fuchs PN, Turk DC. The biopsychosocial approach to chronic pain: scientific advances and future directions. Psychol Bull 2007;133:581-624.

[20] Lindstrom I, Ohlund C, Eek C, Wallin L, Peterson LE, Fordyce WE, et al. The effect of graded activity on patients with subacute low back pain: a randomized prospective clinical study with an operant-conditioning behavioral approach. Phys Ther 1992;72:279-90; discussion 91-3.

[21] Fordyce W. Behavioral methods for chonic pain and illness. St Louis: Mosby. 1976.

[22] Ostelo RW, Koke AJ, Beurskens AJ, de Vet HC, Kerckhoffs MR, Vlaeyen JW, et al. Behavioral-graded activity compared with usual care after first-time disk surgery: considerations of the design of a randomized clinical trial. J Manipulative Physiol Ther 2000;23:312-9.

[23] CBS. Herkomst van personen; allochtonen en migratie (Country of origin of persons; migrants and migration). Centraal Bureau voor de Statistiek, Voorburg / Heerlen. 2003.

[24] Ware JE, Jr., Sherbourne CD. The MOS 36-item short-form health survey (SF36). I. Conceptual framework and item selection. Med Care 1992;30:473-83.

[25] Van der Zee KI, Sanderman R. Het meten van de algemene gezondheidstoestand met de RAND-36: een handleiding (Measuring health status with the RAND-36: a manual); 1993.

[26] Fayers PM, Sprangers MA. Understanding self-rated health. Lancet 2002;359:187-8.

[27] Pearlin LI, Schooler C. The structure of coping. J Health Soc Behav 1978;19:221.

[28] Rosenberg M. Society and the adolescent self-image. Princeton: Princeton University Press. 1965.

[29] Vlaeyen JWS, Kole Snijders AMJ, Boeren RGB, van Eek H. Fear of movement/(re)injury in chronic low back pain and its relation to behavioral performance. Pain 1995;62:363-72.

[30] Hollis S, Campbell F. What is meant by intention to treat analysis? Survey of published randomised controlled trials. BMJ 1999;319:670-4.

[31] Schutgens CAE, Schuring M, Voorham AJ, Burdorf A. Changes in physical health among participants in a multidisciplinary health programme for long-term unemployed persons. submitted.

[32] Guzman J, Esmail R, Karjalainen K, Malmivaara A, Irvin E, Bombardier C. Multidisciplinary rehabilitation for chronic low back pain: systematic review. BMJ 2001;322:1511-6.

[33] Patel S, Greasley K, Watson PJ. Barriers to rehabilitation and return to work for unemployed chronic pain patients: a qualitative study. Eur J Pain 2007;11:831-40. 


\section{Licence or Publication statement}

The Corresponding Author has the right to grant on behalf of all authors and does grant on behalf of all authors, an exclusive licence (or non exclusive for government

employees) on a worldwide basis to the BMJ Publishing Group Ltd and its licensees, to permit this article (if accepted) to be published in JMG and any other BMJPG products and to exploit all subsidiary rights, as set out in our licence (http://jmg.bmjjournals.com/ifora/licence.pdf). 
Figure 1 Flow of participants through the phases of the trial.

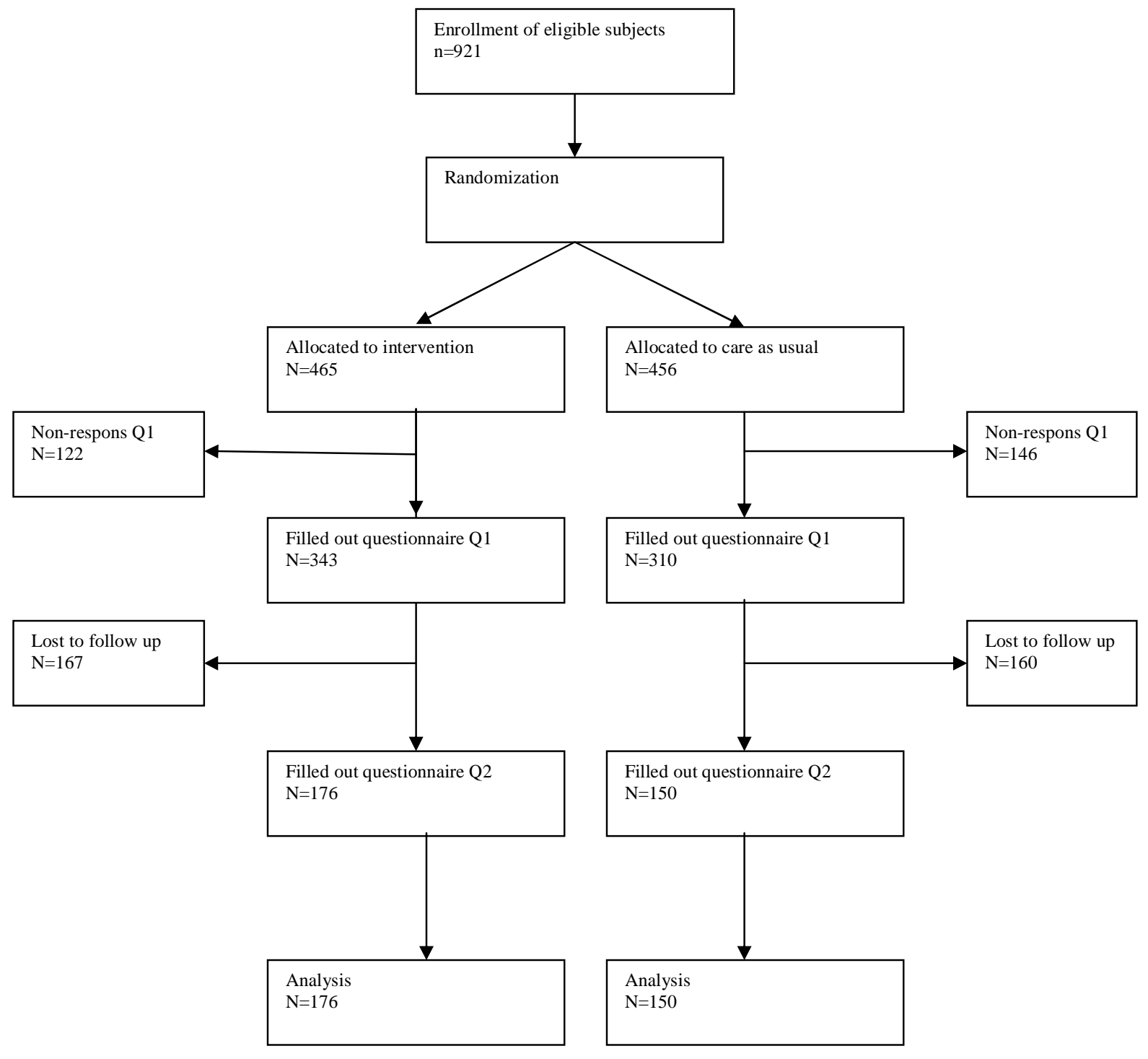

